\title{
Transient third-degree AV block following sugammadex
}

\author{
Ikue Saito $\cdot$ Yoshimune Osaka $\cdot$ Muneaki Shimada
}

Received: 26 November 2014 / Accepted: 12 January 2015/Published online: 12 February 2015

(C) Japanese Society of Anesthesiologists 2015

To the Editor:

A 64-year-old female undergoing abdominal surgery developed transient third-degree atrio-ventricular block (IIIAVB) after a dose of sugammadex. She had no noteworthy abnormalities on the ECG (ESM Fig. 1A) or of the serum electrolytes and no history of allergy or sugammadex usage. After the epidural catheter was inserted, general anesthesia was induced with propofol, fentanyl, and rocuronium, and maintained with desflurane, remifentanil, and rocuronium. Her hemodynamics remained stable (the operation time $559 \mathrm{~min}$, bleeding $709 \mathrm{ml}$ ). When she regained consciousness, sugammadex was administered. Then IIIAVB was developed $4 \mathrm{~min}$ after $200 \mathrm{mg}$ sugammadex administration (ESM Fig. 1B). The ECG converted to a wide $\mathrm{QRS}$ pattern after $0.5 \mathrm{mg}$ of atropine, and $0.1 \mathrm{mg}$ of epinephrine administration, to sinus rhythm within few minutes (ESM Fig. 1C, D). The examination about her ECG was uneventful after surgery.

Anaphylaxis has been reported as an adverse reaction to sugammadex [1]. Animal study and several clinical reports suggest that allergic reactions are the possible cause of
AVB [2, 3]. Considering the allergic reaction to sugammadex, we should have checked plasma level of histamine and tryptase.

Conflict of interest None.

\section{References}

1. Pühringer FK, Rex C, Sielenkämper AW, Claudius C, Larsen PB, Prins ME, Eikermann M, Khuenl-Brady KS. Reversal of profound, high-dose rocuronium-induced neuromuscular blockade by sugammadex at two different time points: an international, multicenter, randomized, dose-finding, safety assessor-blinded, phase II trial. Anesthesiology. 2008;109:188-97.

2. Dai W, Zhou FW, Song QJ, Li YJ, Deng HW, Xiong XM. Protective effects of calcitonin gene-related peptide on guinea-pig cardiac anaphylaxis. Naunyn Schmiedebergs Arch Pharmacol. 2000;361:161-5.

3. Patterson LJ, Milne B. Latex anaphylaxis causing heart block: role of ranitidine. Can J Anaesth. 1999;46:776-8.
Electronic supplementary material The online version of this article (doi:10.1007/s00540-015-1980-5) contains supplementary material, which is available to authorized users.

I. Saito · Y. Osaka $(\bowtie) \cdot$ M. Shimada

Department of Anesthesiology, Tokyo Metropolitan Ohtsuka

Hospital, 2-8-1 Minami-ohtsuka, Toshima-ku, Tokyo 170-8476, Japan

e-mail: bluesapphire1226@gmail.com 